\title{
Orientalismo a contrapelo: paradojas postcoloniales y contra-utopía en Aux États-Unis d'Afrique de Abdourahman Waberi
}

Maria Mar Garcia

Universidad Autónoma de Barcelona

RESUMO: O ARTIGO SE PROPÕE A REVELAR COMO, SERVINDO-SE DE PROCEDIMENTOS ASSOCIADOS A UMA ESTÉTICA PÓS-MODERNA, ABDOURAHMAN WABERI, ESCRITOR NASCIDO EM DJIBOUTI, EM SEU ROMANCE AUX ÉTATS-UNIS D'AFRIQUE (2006) PROPÕE UM EXERCÍCIO DE FICÇÃO POLÍTICA. TOMANDO COMO PONTO DE PARTIDA APPIAH E A SUA CRÍTICA À ASSOCIAÇÃO AUTOMÁTICA DE CONCEITOS COMO PÓS-MODERNISMO E PÓS-COLONIALISMO, PROCURA-SE DEMONSTRAR QUE A ESTÉTICA PÓS-MODERNA TORNA AMBÍGUA E DIFICILMENTE ACEITÁVEL A CONDIÇÃO PÓS-COLONIAL DO ROMANCE, OU DE OUTRO MODO, EXIGE UMA REVISÃO DO QUE SE TEM ENTENDIDO ATÉ HOJE POR “LITERATURA PÓS-COLONIAL".

ABSTRACT: THE ARTICLE AIMS TO REVEAL HOW, BY MAKING USE OF PROCEDURES ASSOCIATED WITH A POSTMODERN AESTHETIC, ABDOURAHMAN WABERI, DJIBOUTI BORN WRITER, IN HIS NOVEL AUX ÉTATS-UNIS D'AFRIQUE (2006) PROPOSES AN EXERCISE IN POLITICAL FICTION. TAKING AS A STARTING POINT APPIAH AND HIS CRITICISM OF THE AUTOMATIC ASSOCIATION OF CONCEPTS SUCH AS POSTMODERNISM AND POSTCOLONIALISM, WE SEEK TO DEMONSTRATE THAT THE POSTMODERN AESTHETIC MAKES AMBIGUOUS AND HARDLY ACCEPTABLE THE CONDITION POSTCOLONIAL OF THE NOVEL, OR OTHERWISE, IT REQUIRES A REVIEW OF WHAT IS UNDERSTOOD UNTIL TODAY AS "POST-COLONIAL LITERATURE".

PALAVRAS-CHAVE: PÓS-COLONIALISMO, PÓS-MODERNISMO, FICÇÃO POLÍTICA, ABDOURAHMAN WABERI, APPIAH.

KEYWORDS: POSTCOLONIALISM, POSTMODERNISM, POLITICAL FICTION, ABDOURAHMAN WABERI, APPIAH. 
nstalándose en una estética marcadamente postmoderna - elevada concentración de intertextualidad, ironía, parodia, pastiche, etc. - centrada en la inversión carnavalesca (Bajtin) del orden establecido - aquí, el Norte, paupérrimo y sometido a guerras tribales y a epidemias sin fin, y el Sur, una confederación africana omnipotente cuyos habitantes poseen una fe inquebrantable en su superioridad racial, intelectual y económica -, Waberi propone en Aux ÉtatsUnis d'Afrique (2006) un brillante ejercicio de política-ficción. Paradójicamente, teniendo en cuenta el enfoque y la temática escogidos y el nomadismo intelectual y literario que siempre ha reivindicado Waberi, la novela parece poco permeable a la desestabilización de entidades fijas como el binomio Norte-Sur que comportan los flujos de imágenes y de individuos propios del actual contexto globalizado y tecnológico (Appadurai, 2005:65). Siguiendo a Appiah en su crítica contra la asociación automática de dos nociones tan controvertidas y pluri-significantes como son Postmodernidad y Postcolonialismo, se pone de manifiesto que la estética postmoderna vuelve ambigua y paradójica la condición postcolonial de la novela de Waberi. La imitación (mimicry) a partir de la inversión del orden establecido no conduce de manera clara a la activación de la capacidad de iniciativa y de reacción del subalterno (agency) fuera del pastiche y de la parodia, como si esto último sólo fuese posible mediante la suplantación del lugar del Otro en un mundo estático que prolonga las formas de dominación coloniales. La respuesta que ofrece la novela a la pregunta formulada por Spivak en "Can the subaltern speak?” (1988) es que, para poder hablar, el subalterno debe suplantar al Euro-Americano, convirtiéndose así en una especie de ventrílocuo. ¿Puede afirmarse, entonces, que la mimicry teorizada por Bhabha (1994, pp. 85-92) conduce a una forma de contra-poder como parecería presuponer en un primer momento la inversión Norte/Sur propuesta? ¿Hasta qué punto consigue esta ventriloquia superar el silencio de Viernes, cuya palabra resulta inaudible al habérsele cortado la lengua, en la particular transformación de Robinson Crusoe que Coetzee propone en Foe (1986)?

El nomadismo intelectual y literario que Abdourahman Waberi (Yibuti, 1965), uno de los escritores más notables y originales de las letras africanas en lengua francesa, ha venido reivindicando desde el inicio de su carrera lo sitúa en la órbita de los autores como Rusdhie o Naipaul que navegan entre los confines de lo postcolonial y lo postmoderno. Quienes estén familiarizados 
con las teorías de Bhabha - Tercer espacio - o de Glissant - identidad rizoma, Caos-Mundo -, pueden reconocer en la escritura de Waberi las obsesiones propias de las ficciones que celebran la hibridación y el descentramiento y que invitan a pensar el mundo más como circulación permanente entre formas fluidas y difusas que como estructura formada por identidades fijas y estables. La escritura nómada de Waberi ilustra las posibilidades aparentemente infinitas de la hibridación que, ensalzada como modelo teórico y literario, ha conseguido imponerse en el campo postcolonial ${ }^{1}$. Con Aux États-Unis d'Afrique (2006), Waberi parece, sin embargo, alejarse del nomadismo para, instalándose en una estética marcadamente postmoderna - elevada concentración de intertextualidad, ironía, parodia, pastiche, etc. - y sirviéndose de la vieja estrategia de la inversión del orden establecido - aquí, el Norte y el Sur -, elaborar un brillante ejercicio de política-ficción. Ajeno a los flujos de imágenes y de individuos propios del actual contexto globalizado y tecnológico (APPADURAI, 2005:65) ${ }^{2}$, Aux États-Unis d'Afrique ilustra a la perfección la visión carnavalesca del mundo (Bajtín) que tanto ha marcado la estética de la Postmodernidad. Sin embargo, siguiendo a Appiah y su crítica contra la asociación automática de dos nociones tan controvertidas y pluri-significantes como son Postmodernidad y Postcolonialismo, se pone de manifiesto que la estética postmoderna vuelve ambigua y paradójica la condición postcolonial de la novela de Waberi. A pesar de que el relato ilustra muchas de las cuestiones privilegiadas por los estudios postcoloniales, la imitación (mimicry) a partir de la inversión del orden establecido no conduce de manera clara a la activación de la capacidad de iniciativa y de reacción del subalterno (agency) fuera del pastiche y de la parodia, como si ello sólo fuese posible mediante la suplantación del lugar del Otro en un mundo estático que prolonga las formas de domi-

1. Su particular forma de conjugar cuento, leyenda y crónica periodística superponiendo las imágenes de un país reconstruido desde el exilio voluntario a la actualidad política y explorando desde diferentes ángulos los márgenes de la Historia se pone de manifiesto tanto en su trilogía en torno a Yibuti (Le Pays sans ombre, 1994; Cabier nomade, 1996; Balbala, 1997) como, después de un personal testimonio sobre el horror del genocidio de Ruanda (Moisson de crânes, 2000), en Rift routes rails (2001) o Transit (2003).

2. En Passage des larmes (2009), Waberi corrige su visión anacrónica de un mundo que quiere ser contemporáneo, como demuestran muchas referencias, pero que parece inspirarse más de la época de la guerra fría que de la actual, elaborando un thriller político en un escenario dominado por las multinacionales tecnológicas y el terrorismo y acompañado de una original meditación sobre el Ángel de la Historia bajo los auspicios de otro nómada irreductible: Walter Benjamin. 
nación coloniales. La respuesta que ofrece la novela a la pregunta formulada por Spivak en "Can the subaltern speak?" (1988) es que, para poder hablar, el subalterno debe dejar de serlo trasladando su condición al Euro-Americano. En la medida en que la voz africanizada mediante todo tipo de referencias que se toma una revancha convirtiéndose en dominante, parece la de un ventrílocuo, ¿puede afirmarse que la mimicry teorizada por Bhabha (1994, pp. 85-92) conduce a una forma de contra-poder? Desde esa perspectiva, Waberi parece prolongar el silencio de Viernes en Foe (1986) de Coetzee (particular transformación de Robinson (Crusoe), cuya palabra resulta inaudible al habérsele cortado la lengua.

Entroncando con la tradición del cuento filosófico, la novela pone patas arriba el paradigma mundial Norte-Sur. Waberi propone una recreación del ideal político de un continente africano indivisible, próspero y solidario iniciado por el jamaicano M. Garvey, cuyo sueño de redención inspiró a panafricanistas e independentistas. Aunque inaccesible para la mayoría de los caucásicos que han tenido la desgracia de nacer en algún mísero rincón de la postrada Euro-América, el African Way of Life se ha impuesto como modelo indiscutible de crecimiento y de prosperidad. En este boyante Eldorado africano tienen cabida el ultramoderno aeropuerto Léopold Sédar Senghor Internacional, la tecnología punta del Silicium Rift Valley, la creación artística más original y los intelectuales más eminentes -recogidos en la prestigiosa Africana Encyclopaedia-, las proezas espaciales de los astronautas de Mali y Liberia o las actividades de los cascos azules nigerianos para restablecer la paz en Quebec. Los inconvenientes de esta sociedad del bienestar, donde se toma Neguscafé, se compran muebles en Nka y en la que el somalí es la lengua de los negocios y de la diplomacia, son previsibles: el aumento de la obesidad que provoca el consumo habitual de hamburguesas Mac Diop regadas con Africola o Papesy, la llegada masiva de prostitutas procedentes de Mónaco o del Vaticano, y, sobre todo, el peligro blanco, la terrible lacra de la inmigración, verdadero azote de las opulentas megalópolis africanas. Hordas de desarrapados perezosos y carentes de ambición, austríacos, británicos, suecos, canadienses, franceses, españoles, todos expuestos al sida o a la lepra y a expensas de la ayuda humanitaria procedente de Haití o del Sahel, sueñan con dejar atrás las milicias paramilitares, las guerras interétnicas, las catástrofes naturales, el hambre y las epidemias para alcanzar en pateras la costa de Argel o las playas de Djerba. 
Esta incisiva fábula política se presenta, así, como el negativo de la recurrente instantánea afro-pesimista que nos ofrecen invariablemente los medios. Paralelamente a la emergencia de este mundo de ciencia-ficción se despliega, narrada en segunda persona a diferencia del resto del relato, en tercera persona, la historia personal de Maya, artista cotizada de Eritrea e intelectual comprometida con la causa alter-mundialista. Maya es hija adoptiva de Docteur Papa. Este ha dedicado su vida a luchar contra las epidemias que devastan las tierras de Euro-América y encontró a la niña durante una misión humanitaria en la húmeda y mísera Normandía, región enfrentada en una guerra tribal con la vecina Bretaña por disputarse ambas el Monte Saint-Michel. En el momento en el que se inicia el relato, la madre adoptiva de Maya, amante de música clásica y de filología somalí, tiene los días contados a causa de una enfermedad terminal (la inversión se extiende a todos los ámbitos, de modo que las epidemias y las enfermedades producidas por condiciones de vida insalubres se reservan a Euro-América). Maya decide iniciar un difícil viaje de reencuentro con sus dolorosos orígenes. Su viaje a Francia y el cuestionamiento sobre su identidad de blanca adoptada en un mundo regido por el canon de belleza negro permiten introducir el tema de la búsqueda de identidad aunque transformando considerablemente el script del bildungsroman africano a la Camara Laye. Si Waberi también escoge al personaje por su representatividad, el relato de la búsqueda de identidad de Maya ha dejado de remitir a los clásicos africanos para recordar a las narraciones de hijos adoptivos que abundan en las librerías y que detallan el periplo de su regreso al país de origen y el reencuentro, en medio de dudas y de miedos, con su familia biológica. Aunque, en el caso de Maya, conviene hablar de desencuentro: nada la une con los que dejó atrás y, ante la visión insoportable de la injusticia y la miseria, Maya regresa a su país para dedicarse al arte y a la creación y seguir ayudando, desde la distancia, a los excluidos y a los marginales. Ello confirma, en el plano individual, el tratamiento que recibe la alteridad en el plano colectivo, esto es, en la descripción del imperio africano y de su no-relación con el extranjero. En ambos casos se trata de una distancia insalvable entre Yo y el Otro, de una alteridad radical e infranqueable.

La inversión sistemática del orden establecido, dirigido a despertar en el lector una reacción crítica y una toma de conciencia mediante la observación del universo familiar como si fuese extranjero y viceversa, es un recurso li- 
terario que se remonta a la Antigüedad. La literatura utópica (Histoire comique des états et empires de la lune de Cyrano de Bergerac, 1656) y la novela de viajes y de aventuras (Viajes de Gulliver, Jonathan Swift, 1726) ofrecen diversas muestras de dicha práctica que culmina, durante la Ilustración, con las Lettres persanes (Montesquieu, 1721) y que utiliza, aunque de modo menos sistemático, Voltaire en Candide (1758) o en L’Ingénu (1767). Más recientemente, esta vieja fórmula ha conseguido éxitos notables como la novela de ciencia-ficción Planet of apples (Pierre Boulle, 1963) y sus posteriores secuelas cinematográfica y televisiva. La empatía inmediata que despiertan en el espectador unos infelices humanos sometidos a la esclavitud por sus antecesores en la cadena de la evolución parece mitigarse, sin embargo, cuando se trata de razas. La técnica del "negativo fotográfico", que transforma lo negro en blanco y viceversa da lugar a la rama melanocrática de la utopía política, que cuenta con diversos e ilustres representantes y cuyo análisis pormenorizado supera el objeto de estas páginas. Sí conviene referirse a la figura de Juan Latino, (1516-circa 1594), considerado el primer poeta negro en una lengua europea (latín). El africano Latino, que habría llegado a España cuando contaba unos doce años y que habría sido esclavo antes de realizar estudios universitarios y de convertirse, según algunas crónicas, en profesor en la Universidad de Granada, dedicó lo esencial de su obra a celebrar el linaje de los Austrias y sus victorias. En sus circunstancias, los "etíopes" o africanos de sus poemas sólo podían aparecer como salvajes paganos cuya salvación dependía de su sometimiento a la fe católica. Con todo, en un inesperado fragmento del prefacio de su Epigrammatum Liber, Latino solicita permiso a Felipe II para cantar las plegarias de sus hermanos, llegando a comentar, con sorprendente atrevimiento, que, del mismo modo que su cara negra no es del agrado de los ministros del monarca, tampoco lo sería una cara blanca para los hombres de Etiopía ( $c f$. DATHORNE, 1974, pp. 67 et seq.). Teniendo en cuenta la situación personal del poeta, su audaz, aunque rápida, incursión en la práctica que nos ocupa no pudo pasar desapercibida. Más reciente y perteneciente al ámbito francófono es Empsaël et Zoraïde ou les blancs esclaves des noirs à Maroc, obra de teatro de Bernardin de Saint-Pierre - autor de sensibilidad rousseauniana más conocido por su novela Paul et Virginie (1788) - escrita hacia 1793, es decir, coincidiendo prácticamente con la abolición oficial de la esclavitud en las colonias francesas (1794). 
La otra novela francófona a la que nos referiremos, La revanche de Bozambo de Bertène Juminer, escritor de la Guayana francesa, fue publicada en 1968, en el momento álgido de las luchas raciales encabezadas por Martin Luther King, Malcolm X y los Black Panthers y por las reivindicaciones de los flamantes países independientes del Tercer Mundo. En esta ficción de reminiscencias orwellianas, que comparte sin embargo con el título anterior la escasa atención recibida por parte de la crítica, Juminer utiliza una estrategia muy similar a la de Waberi: la E. O. E. ("Europe occidentale baoulienne") se haya bajo el yugo de la "misión civilizadora" y el poder fascista de la república africana de Baoulie, cuyo gobierno decreta el cambio de nombre de las calles y reordena sin miramientos el territorio, haciendo de Bantouville la capital colonial africana situada en el corazón de Europa; mientras, los blancos sufren interrogatorios y descargas policiales y son sometidos a todo tipo de vejaciones.

Así pues, a pesar de la originalidad de su novela, Waberi sólo es el continuador de una tradición que le permite desautomatizar la mirada del lector mediante la elaboración de un mundo que, a la manera de la etnografía de proximidad practicada por un Marc Augé, produce un sentimiento de extrañamiento en el lector. El uso del gentilicio "helvético", por ejemplo, en lugar del más neutro y esperado "suizo" nos advierte del carácter artificial y poco utópico en algunos aspectos de la Confederación helvética, proyectando una sombra sobre su modelo de paz y de prosperidad. Este país, cuyo tamaño se compara, en la novela, con el de un sello postal, aparece situado en un territorio despoblado e inhabitable a causa de la nieve que cubre dos tercios de su superficie. En un desierto helado, apenas más inhóspito que otros territorios euro-americanos, los enfrentamientos ancestrales entre "etnias" - aquí, los luteranos helvéticos, que viven en el norte y son más ricos, y los católicos, que viven en el sur y se dedican a la tierra- son la causa de todos los males:

Les frontières linguistiques lacèrent ce costume de clown appelé la Suisse et connu uniquement pour ses mercenaires, son couteau à multiples usages et ses crétins goitreux. Elles divisent les montagnes, elles partagent les lacs, elles isolent les villages les uns des autres; elles séparent les maisons à l'intérieur du même village et, dans le café du village, elles passent entre les bouteilles posées sur le comptoir. (p. 35). 
La ficción llama la atención sobre aquello que, a fuerza de ser presentado como cierto acaba siéndolo, y sobre el lastre de convenciones y creencias colectivas que acarrea toda lengua. La denominación "Euro-América" viene acompañada, en la ficción, de los mismos valores negativos que acompañan, en los discursos mediáticos, la imagen estereotipada del continente africano: miserabilismo, pesimismo, descuido homogeneizador, visión anacrónica fruto de la ignorancia, etc. $\mathrm{Y}$, al revés, el narrador subraya la diversidad y la riqueza de los Estados Unidos de África. Si la enorme distancia que separa en el mapa los diferentes centros neurálgicos que posee el imperio de los Estados Unidos africanos concebido por Waberi, sorprende, sólo tenemos que cambiar Mascate por Helsinki o Banjul por Vancouver para que deje de hacerlo. Los cristales correctores de las gafas que nos proporciona el viejo artificio de la inversión evidencian a cada línea hasta qué punto las representaciones aparentemente más neutras son siempre el resultado de una visión orientada del mundo. El resultado es fulminante, como cuando un estudiante recorre las páginas de un atlas extranjero y descubre de repente que su país no está en el centro del mundo. Como en los discursos mediáticos, el discurso de ficción sobre Euro-América se basa en un análisis parcial, insuficiente o incluso ausente de las razones que han llevado a la situación actual. En su lugar, predomina el registro emocional, en el cual compasión, solidaridad ante la desgracia y la injusticia y aceptación de la desigualdad como si de un destino implacable se tratara (afro-pesimismo) resultan inextricables.

A imagen (invertida) de lo que ha venido sucediendo, el imperio africano de ficción que propone Waberi se dota de una dimensión diacrónica, o sea, de una gloriosa historia de la que parecen carecer los Euro-americanos, presentados, a la manera de los discursos antropológicos, como esencias estables y fijas. La articulación de explicación de corte historicista, por un lado, y descripción etnográfica por otro, da lugar a un impecable ejercicio de estilo que, al intercambiar los roles entre productor y destinatario, observador y observado, consigue pone en tela de juicio la separación habitual entre ambos discursos: el histórico, reservado a las civilizaciones con escritura, y el etnográfico, reservado a los pueblos considerados primitivos. El narrador se refiere a los euro-americanos designándolos como "caucásicos de etnias diversas" y despojándolos de cualquier otro atributo que permita individualizarlos. Aduciendo el carácter impronunciable de su nombre, se vuelve a bautizar a los 
inmigrantes. Es el caso de Yacouba, privado de su nombre, esto es, de su singularidad, y convertido, mediante la acumulación de atributos étnicos, en una especie de prototipo archi-helvético digno de un museo etnográfico, de paradigma imaginario del bomo belveticus.

Como en las películas históricas de bajo presupuesto rodadas en estudios de cartón piedra y con extras a quienes nadie ha advertido de que se quiten el reloj de pulsera antes de ponerse la túnica de romano, Waberi acumula anacronismos que descontextualizan las descripciones de los "caucásicos" intensificando la naturaleza retrógrada y primitiva de éstos. Su existencia parece situarse en una tenebrosa Edad Media sin fin en la que coexisten pueblos que, en la historia real, han vivido en épocas distintas. Así, "íbero" (pueblo pre-romano) designa a los actuales habitantes de la península ibérica. Pero la imprecisión no sólo afecta al tiempo: Yacouba, inmigrante "helvético", ha nacido en una favela [sic] cerca de Zurich (p. 11) y habla "petit-blanc" - este neologismo se elabora a partir de la expresión consagrada "petit-nègre", que ha pasado a designar todo uso simplificado e incorrecto de la lengua francesa independientemente de la procedencia geográfica del hablante. Cuando se trata de bárbaros, parece decirnos el narrador, los errores y las inexactitudes carecen de importancia.

Los Estados Unidos africanos, en cambio, poseen una historia muy antigua, un pasado glorioso y un patrimonio cultural inigualable que son recalcados también en el plano formal mediante la acumulación de nombres propios de personalidades, instituciones o aspectos culturales y la utilización de construcciones sintácticas y de términos arcaicos, cultos o de uso literario: así, el adjetivo "preux" (esforzado), en lugar del más neutro "valiente", antepuesto al topónimo "regne d'Oman" (p. 12), transmite a este sultanato, situado en la península aràbiga, el aura de maravilloso del género de caballerías, el cual pasa a tener el mismo valor orientalista que una referencia a las Mily una noches en boca de un autor romántico. Conviene señalar, además, el recurso al genitivo latino utilizado en los títulos de los capítulos o al tono épico para dar cuenta de los orígenes del modelo indiscutible de crecimiento y de prosperidad que es el African Way of Life.

Se le puede reprochar a Waberi que no abandone la dicotomía, aunque sea invertida, nosotros-ellos, civilización-barbarie que la mirada postcolonial intenta desmantelar. Su construcción de un Otro radical, irreductible en su alte- 
ridad parece reactivar la relación colonial. ¿Cómo podría una escritura consagrada a exhibir, reforzándolos, discursos dogmáticos y homogéneos sobre el Otro romper el cordón umbilical colonial? Conviene señalar, sin embargo, que la utopía africana es también objeto de críticas desde el interior, sobre todo por parte de Maya y de quienes, como ella, no se reconocen en un modelo de estado imperialista. La utopía africana de Waberi tiene, desde esa perspectiva, mucho de contra-utopía. No en vano, al final del relato, Maya decide regresar a su país y consagrarse a su obra: “Tu te consumeras dans l'exécution de ton œuvre” (p. 231). Maya entiende que, para transformar las cosas, debe trabajar, como Candide, cada día en su jardín. Así, la novela de Waberi se distingue de todas sus predecesoras, como también lo hace del film Africa Paradis (2007), del director Sylvestre Amoussou, que (dejando a un lado la escasez de medios con la que se realizó), también proyecta una mirada idealizada sobre África. La Historia real ya se ha encargado de hacer realidad algunas inversiones utópicas, pero los esclavos americanos que se instalaron en Liberia reprodujeron los esquemas de poder que habían conocido anteriormente y la revolución haitiana capitaneada por el esclavo liberto Toussaint Louverture parece perderse en la memoria, por no referirnos a la utilización del culto a los valores negros practicada por los dictadores africanos para fortalecer su poder. De ahí la necesidad de actualizar la inversión despojándola de toda idealización, de convertir la utopía en contra-utopía. Cabe igualmente tener en cuenta el carácter abigarrado del estilo de Waberi, que elabora un patchwork de registros y de géneros en el que las formas enumeradas más arriba se alternan con otras coloquiales o con argot, y el tono divertido y desinhibido del narrador interviene en medio de un pasaje lleno de afectación y pomposidad.

La novela ilustra, así, las tesis de Dipesh Chakrabarty en su ensayo Provincializing Europe. Chakrabarty denuncia la dependencia de la tradición europea y de sus protocolos discursivos (historicismo, política), base del universalismo en el que se sustenta el proyecto de la Modernidad, sobre todo a partir de la Ilustración. Esta visión condena a los países exteriores a la misma a convertirse en un mero simulacro, defectuoso o fallido del modelo liderado por Europa, a existir en tanto en cuanto pueden situarse respecto de dicho modelo. Si la novela es una magistral parodia de los discursos colonialistas, la caricatura no conduce sino a una muy tímida relación, a través de Maya, entre dos mundos mutuamente impermeables. Waberi construye una suerte de tratado neo-orientalista 
que, aunque a la inversa, sigue refiriéndose a dos mundos opuestos, antagónicos. En este sentido, la crítica que James Clifford dirige contra Said bien podría aplicarse a esta novela que "appears to mimic the essentializing discourse it attacks" (CLIFFORD, 1988:262). En tanto en cuanto el discurso sobre el Otro constituye un inmenso a priori que lo reduce a la condición de categoría inamovible, la contra-utopía de Waberi se construye a un elevado precio: condenar a los Africanos a una especie de simulacro del proyecto europeo, reproducido con todos sus defectos. El inteligente ejercicio de estilo no se hace desde un lugar propio de enunciación más allá de la imitación ingeniosa. Sólo ocupando el lugar predeterminado del Yo dominante y suplantando su personalidad, puede el Otro autorizarse a abandonar su condición de subalterno.

Pero, tras la apariencia de divertimento ligero profuso en juegos de palabras ingeniosos, referencias intertextuales y guiños dirigidos a un lector cultivado, el mundo al revés, inspirado de la estética carnavalesca teorizada por Bajtín, que construye Waberi acaba desestabilizando tanto el proyecto eurocentrista, ridiculizado mediante el procedimiento de la inversión, como el afrocentista, que no sale mejor parado. Más allá del jubiloso inventario que permite elaborar este negativo fotográfico, el lector se ve despojado paulatinamente de cualquier tentación maniquea; todas y cada una de sus certezas se diluyen para acabar atrapado en un torbellino de paradojas que desmantela, de antemano, cualquier intento de fundar un orden estable. Con todo, la inversión sistemática practicada por Waberi en su particular elaboración de un mundo al revés, bien podría ser un sugerente palimpsesto, aderezado al gusto postmoderno y postcolonial (esto último más por temática que por pragmática) de la relación colonial. En ese sentido, resulta sintomático que Kwame Appiah, autor de "Is the Post- in Postmodernism the Post- in Postcolonial?", sea convertido, en la ficción, en el autor de una crítica de arte sobre las esculturas de Maya, presuntamente publicada en la Revue noire de arte contemporáneo africano y reproducida en el capítulo veintitrés. El pastiche "a la Appiah" podría leerse como una figura que da cuenta en el texto de la incomodidad que producen en el autor las contradicciones internas de este trabajo literario.

Conviene no ignorar los reproches que, oportunamente, se han hecho a este tipo de literatura, sobre todo, por su dependencia del fetichismo que envuelve tanto al productor como al consumidor en el actual contexto neocapitalista global, y por la ilusión de un localismo que, aunque sea invertido, 
parece remitir al exotismo de siempre (HUGGAN, 2001; BROUILLETTE, 2007). Desde la ironía, la parodia y el pastiche, la novela de Waberi no deja de recurrir a los mismos materiales de siempre, es decir, a los clichés culturales cuya reactivación inteligente y llena de humor sigue deleitando al lector cosmopolita e informado que hace unas décadas descubría el realismo mágico. Ello deja muchos interrogantes abiertos sobre la capacidad de este tipo de novelas para neutralizar los procesos de recepción exotizante de las literaturas africanas. Como señala Pierre Halen, en el caso del sistema literario francófono, existen dos vías para legitimarse como autor: o bien el de la asimilación, mediante la eliminación de los marcadores de identidad extranjeros (caso de un Michaux), o bien el de la especificación, basado en la producción y en la explotación de dichos marcadores (HALEN, 2001:66). Lo que parecería no poder perdonársele a Waberi, es el hecho de decidirse por la segunda sin renunciar a la primera: 'La plus grosse insulte qu'on puisse me faire, c'est me reprocher de m'intéresser à Joyce, sous prétexte que je suis un écrivain du Tiers-Monde". Con Aux États-Unis d'Afrique, el autor confirma su adscripción a la generación des "enfants de la postcolonie" (1998) y su participación en el "Manifeste des 44" por una "Literatura-mundo" (2007) desestabilizando el paradigma colonial y reactivando la vieja técnica de la inversión (mimicry), sin que ésta represente una verdadera amenaza más allá de la réplica. ¿Debe ello ser considerado como una impostura o, simplemente, como una postura?

\section{Referências Bibliográficas}

APPADURAI, Arjun. Après le colonialisme. Paris: Payot, 2005.

APPIAH, Kwame Anthony. "Is the Post- in Postmodernism the Post- in Postcolonial?” In Critical Inquiry, vol. 17, $\mathrm{n}^{\circ}$ 2, 1991:336-357.

BHABHA, Homi. The location of culture. Londres: Routledge, 1994.

Brouillette, Sarah. Postcolonial writers in the Global Literary Marketplace. New York: Palgrave Macmillan, 2007.

CHAKRABARTY, Dipesh. Provincializing Europe. Postcolonial Thought and Historical Difference. Princeton: Princeton University Press, 2000.

CLIFFORD, James. “On Orientalism” In CLIFFORD, James. The Predicament of Culture: Twentieth-Century Ethnography, Literature, and Art. Cambridge, MA: Harvard University Press, 1988, pp. 255-276. 
DATHORNE, Oscar Ronald. The Black Mind. A History of African Literature. Minneapolis: University of Minnesota Press, 1974.

HALEN, Pierre. "Notes pour une topologie du système littéraire francophone". In Diop, Papa Samba et Lüsebrink, Hans-Jürgen (dir.). Littératures et sociétés africaines. Mélanges offerts à János Riesz. Tübingen: Gunter Narr Verlag, 2001. p. 55-67.

HUGGAN, Graham. The Postcolonial Exotic: Marketing the Margins. London: Routledge, 2001.

LITTLE, Roger. “Fables of Melanocracy: 'Race' Reversals in French Literature”. In Forum for Modern Language Studies, vol. 37, 1, 2001:1-14.

MUDIMBE, Valentin-Yves. The Invention of Africa. Gnosis, Philosophy and the Orther of Knowledge. Bloomington: Indiana University Press, 1988.

SAID, Edward W. Orientalism. Nova Iorque: Vintage Books, 1979.

SPIVAK. "Can the Subaltern speak ?" In NELSON, Cary; GROSSBERG, Lawrence. Marxism and the Interpretation of Culture. Chicago: University of Illinois Press, 1988:271-313.

WABERI, Abdourahman. "Les enfants de la postcolonie. Esquisse d'une nouvelle génération d'écrivains francophones d'Afrique noire". In Notre Librairie, 135, 1998:8-15. WABERI, Abdourahman. Aux États-Unis d'Afrique. Paris: Lattès, 2006.

Recebido em 03 de abril e aprovado em 06 de maio de 2010. 